\title{
Investigations of selected properties of pharmacologically active compounds by chromatographic and potentiometric methods on the chrysin example
}

\author{
${ }^{1}$ Janusz Pusz, ${ }^{2}$ Wojciech Zapała, ${ }^{1}$ Bogdan Papciak \\ ${ }^{1}$ Department of Inorganic and Analytical Chemistry \\ ${ }^{2}$ Rzeszów University of Technology, Department of Chemical and Process Engineering, Chemical Faculty, \\ al. Powstańców Warszawy 6, 35-959 Rzeszów, Poland, e-mail: bpapciak@prz.edu.pl
}

\begin{abstract}
The RP-TLC method was used to determine the dissociation constant of chrysin (5,7-dihydroxyflavone) in methanol-aqueous $(1: 1 \mathrm{v} / \mathrm{v})$ solutions. In this method the $p K$ value was quantified on the basis of retention data and a retention model. The accuracy of determining the model parameters was analysed using the following statistical criteria: the sum of the squared differences between the experimental and theoretical data, approximation of standard deviation, and the Fisher test. Besides, in this work the potentiometric method was used. Investigations were carried out at ionic strength $\mathrm{I}=0.1$ at $\mathrm{T}=298 \mathrm{~K}$. The dissociation constant were determined using the Rossotti method as well as the numerical method based on the procedures of non-linear curve fitting using Microsoft Excel Solver and the user-defined function. It has been found that the differences in the evaluated $p K$ values were relatively small and did not exceed $1.2 \%$.
\end{abstract}

Keywords: RP-HPLC, retention model, chrysin, dissociation constant.

\section{INTRODUCTION}

Flavonoids are natural products widely distributed in the vegetable kingdom and currently consumed in large amounts in the daily diet ${ }^{1,2}$. Different compounds of the flavonoid class have been distinguished by the number and the position of functional groups, mainly hydroxyls, introduced on the phenyl rings. A multitude of substitution patterns in the two-benzene rings (A and B, Fig.1) of basic structure occurs in nature. Variations in their heterocyclic rings give rise to flavonol, flavones, catechins, flavanones, anthocyanidins and isoflavones. Over 4000 different, naturally occurring flavonoids have been described and the list is still growing. These natural products are interesting as pharmacological agents since they stimulate or inhibit a wide variety of enzyme systems and are potential antibacterial, anticancer and antialergic agents ${ }^{3-5}$. Many of those are biologically active, particularly those able to form quinone group and coordinate metal ions in solutions.

Chrysin (5,7-dihydroxyflavon) is one of the less known flavonoid, and like other flavonoids, is insoluble in water. The solid complexes of several metal ions: $\mathrm{Co}(\mathrm{II}), \mathrm{Ni}(\mathrm{II}), \mathrm{Cu}(\mathrm{II})$, $\mathrm{Cd}(\mathrm{II}), \mathrm{Pb}$ (II) and $\mathrm{Fe}(\mathrm{III})$ with chrysin were separated ${ }^{6}, 7$. Determination of the dissociation constants $(p K)$ of this compound can lead to better understanding of metal-complexing properties of this molecule in the water-methanol solution and allow better separation of this compound from their biological media. The most common methods of $p K$ determination include potentiometry or, if the compounds possess a suitable chromophore, then the spectroscopic methods can be applied.

With water-insoluble compounds, the mixed solvent approach can be exploited. Methanol should be used in the first

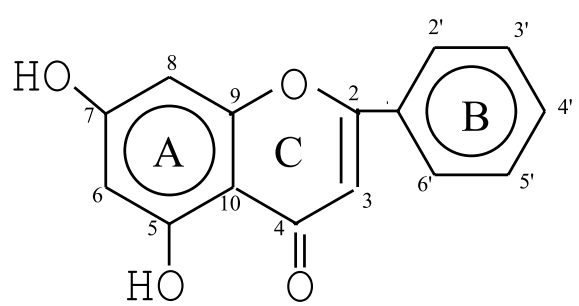

Figure 1. Representation and atomic numbering adopted for chrysin place because there is a lot of information available concerning its effect on the $p K$ value ${ }^{8-12}$.

In this article, the TLC reversed-phase chromatography and potentiometric titration method were used to determine the dissociation constant for chrysin in the water-methanol solution.

\section{EXPERIMENTAL}

\section{Reagents}

Fig. 1 shows the structure and the chemical numbering system of 5,7-dihydroxyflavone. The compound purchased from Sigma was purified by repeated crystallization from ethanol-water. The purity control was performed determining its melting point ${ }^{13}\left(\mathrm{mp}=285^{\circ} \mathrm{C}\right)$ and its TLC chromatographic properties ${ }^{14}$. Sodium hydroxide, perchloric acid, methanol of spectroscopic grade from Fluka, were used without further purification. A CPI-551 digital $\mathrm{pH}$-ionmeter with a combined SAgP-209 W electrode were used in experiments.

The TLC solvents (methanol and water) were chromatographic grade from Merck (Darmstadt, Germany).

\section{Procedures}

\section{Thin-layer chromatography}

Thin-layer chromatography was performed on the $10 \times 3$ $\mathrm{cm}$ RP-18 aluminium sheets (RP-18 $\mathrm{F}_{254}$ HPTLC plates Merck, Darmstadt, Germany) in classical glass chambers. The plates were conditioned for $15 \mathrm{~min}$ in eluent vapours to eliminate the demixing effect. The samples $(2 \mu \mathrm{l})$ of $0,08 \mathrm{mg} / \mathrm{cm}^{3}$ solutions of chrysin in the analyzed mobile phase were spotted to the adsorbent layer. The chromatographic measurements were conducted at constant $\left(20 \pm 1^{\circ} \mathrm{C}\right)$ temperature. As eluents the methanol - phosphate buffer $1: 1(\mathrm{~V} / \mathrm{V})$ solutions within the $\mathrm{pH}$ range $2.0-9.5$ were used. The locations of the spots was determined under UV light $(\lambda=254 \mathrm{~nm})$. In all the cases the spots were symmetric and did not exhibit tailing. The retardation factors were calculated as the average of three measurements. 


\section{Potentiometric method}

The value of the first dissociation constant of chrysin $(p K)$ was determined by the potentiometric titration method. For this purpose, the water-methanol solutions (\%vol. 1:1) of chrysin containing sodium perchlorate were titrated with 0.01 $\mathrm{mol} / \mathrm{dm}^{3}$ sodium hydroxide solution. Potentiometric investigations of the dissociation constant were carried out at chrysin concentrations: $3.2 \cdot 10^{-4}, 3.5 \cdot 10^{-4}$ and $4.0 \cdot 10^{-4} \mathrm{~mol} / \mathrm{dm}^{3}$.

Potentiometric measurements were carried out at $298 \pm 0.2 \mathrm{~K}$, at a constant ionic strength $(\mathrm{I}=0.1)$ maintained by the addition of $2 \mathrm{~mol} / \mathrm{dm}^{3}$ sodium perchlorate solution. The $\mathrm{pH}$-meter was calibrated by titrating the $0.01,0.02$ and $0.03 \mathrm{~mol} / \mathrm{dm}^{3}$ hydrochloric acid solutions with a standard sodium hydroxide solution $(\mathrm{I}=0.1, \mathrm{~T}=298 \mathrm{~K})$.

\section{RESULTS AND DISCUSSION}

\section{RP-TLC}

In this work for the mathematical description of the retardation factor as a function of $p H$ of the mobile phase $\left(R_{f}=f(p H)\right.$ experimental data) the retention model suggested in ${ }^{15}$ as generally valid for ionizable compounds, has been applied:

$k=\frac{p_{1}+p_{2} \cdot 10^{p H-p K}}{1+10^{p H-p K}}$

where: $k$ is retention factor, $p_{i}$ are experimental model parameters,

The aim of this work was to analyse the applicability of the presented above model for the determination of the $p K$ value on the basis of RP-TLC experiments. Therefore, the model, eq.(1), was transformed according to the following relationship:

$$
R_{f}=\frac{1}{1+k}
$$

where $R_{f}$ is retardation factor

The equation constants $\left(p_{i}\right.$ and $\left.p K\right)$ were estimated by a minimization of a sum of the squared differences between the experimental and theoretical data using the Marquardt method $^{\mathbf{1 6}}$. The accuracy of the determination of the model parameters, $p_{i}$, was assessed for the $95 \%$ confidence interval of Student's test. The following statistical criteria were used to assess the accuracy of the proposed model in different HPLC systems:

The sum of the squared differences between the experimental and the theoretical retention data:

$$
S U M=\sum_{i}\left(R_{f \exp }(i)-R_{f \text { theor }}(i)\right)^{2}
$$

Approximation of the standard deviation:

$S D=\sqrt{\frac{S U M}{N-l}}$

The Fisher test:

$$
F=\frac{(N-l) \cdot \sum_{i=1}^{N}\left(R_{f \exp }(i)-\sum_{i} \frac{R_{f \exp }(i)}{N}\right)^{2}}{(N-1) \cdot \sum_{i=1}^{N}\left(R_{f \exp }(i)-R_{\text {ftheor }}(i)\right)^{2}}
$$

where: $\mathrm{i}=1 \ldots \mathrm{N}, \mathrm{N}$ is number of experimental points, 1 is number of the estimated model parameters.

Table 1 specifies the values of the estimated model parameters (eq. (1)) and the values of statistical criteria used for the comparison between the model (eq. (1)) and the experimental data. In Fig. 2 the graphical comparison of the experimental and simulated $R_{f}=f(p H)$ data has been presented.

On the basis of the comparison between the simulated and the experimental data presented in Table 1 and in Fig. 2 it can be concluded that the model proposed in this study (eq. (1)) provides an excellent agreement between the experimental and the theoretical data. The related values of $S U M$ and $S D$ are very low and the value of the Fisher test is relatively high (see Table 1).

Table 1. Estimated model (eq.(1)) parameters and values of statistical criteria

\begin{tabular}{|l|c|c|c|c|}
\hline Model parameter & Value & SD & SUM & F \\
\hline$p_{1}$ & $0.2021 \pm 0.0005$ & & & \\
\cline { 1 - 2 }$p_{2}$ & $0.117 \pm 0.1$ & $510^{-5}$ & 0.003 & 445.8 \\
\hline pK & $7.10 \pm 0.01$ & & & \\
\hline
\end{tabular}

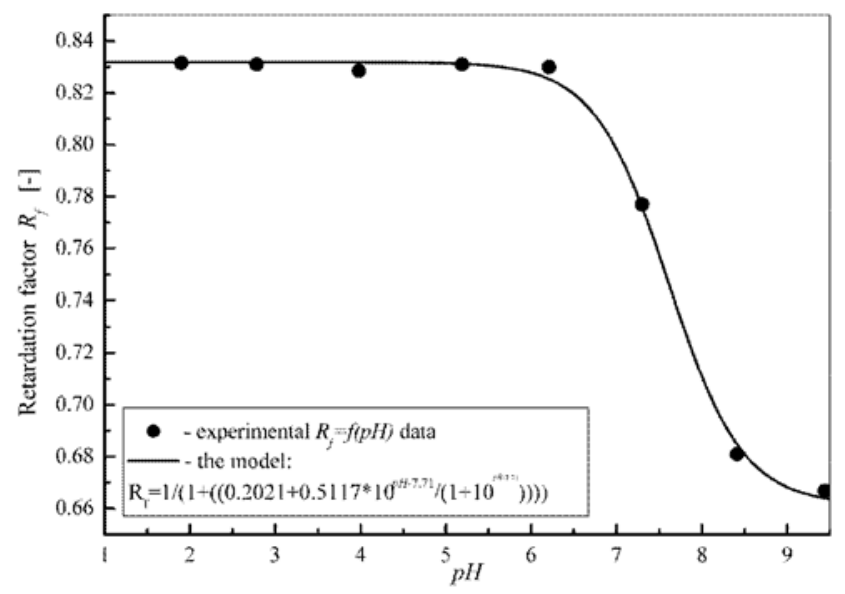

Figure 2. Comparison of the experimental and the theoretical data

\section{Potentiometric method}

The mean number of protons $\bar{j}$ connected with the appropriate base was calculated for each experimentally determined $\mathrm{pH}$ value from the formula ${ }^{17}$ :

$\bar{j}=\frac{H_{t}-\left[H^{+}\right]+K_{w} \cdot\left[H^{+}\right]^{-1}}{c_{L}}$

where: $\left[H^{+}\right]$is equilibrium concentration of hydrogen ions, $K_{w}$ is ionic product of water $\left(K_{w}=2.29 \cdot 10^{-14}\right.$ for $\mathrm{I}=0.1\left(\mathrm{NaClO}_{4}\right)$ and $\left.\mathrm{T}=298 \mathrm{~K}\right), c_{L}$ is total anion concentration of weak acid ions, and $H_{t}$ is total concentration of the protons capable of dissociation.

The $H_{t}$ and $c_{L}$ values were calculated from the analytical composition of the titrated solutions:

$H_{t}=\frac{j \cdot c_{0 L} \cdot V_{L}-c_{0 Z} \cdot V_{Z}}{V_{Z}+V_{L}}$

$c_{L}=\frac{c_{0 L} \cdot V_{L}}{V_{Z}+V_{L}}$

where: $c_{0} \mathrm{z}$ and $c_{0 L}$ are initial concentrations of titrant and chrysin respectively, $V_{L}$ is initial volume of chrysin solution, $V_{Z}$ is volume of titrant, and $j$ is number of protons capable of dissociation.

Based on the results obtained, the chrysin formation curve was plotted (Fig. 3) and it was found that the plot course within the $\mathrm{pH}$ range $5.5-9.0$ does not depend on the concentration of the compound under examination, which means that 


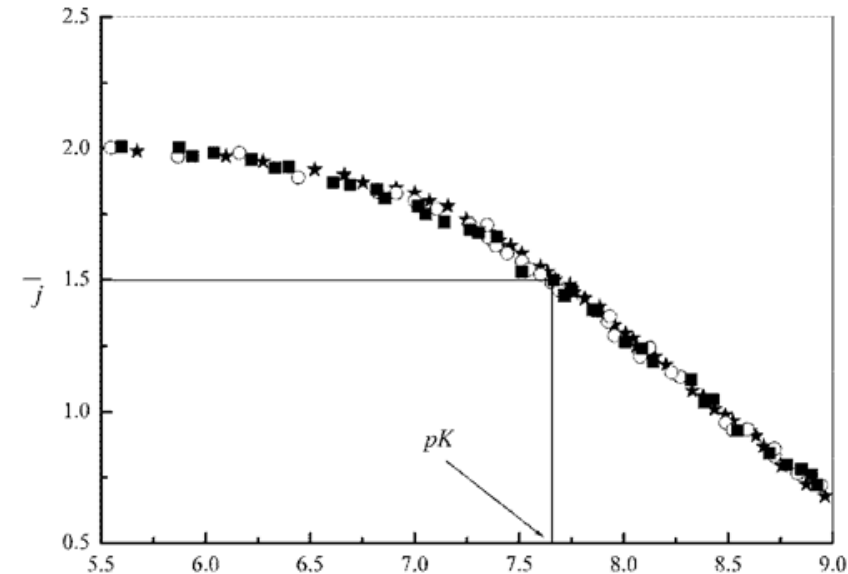

Figure 3. Formation curves of chrysin at the concentrations of $3.2 \cdot 10^{-4}(*), 3.5 \cdot 10^{-4}(\mathrm{O})$ and $4.0 \cdot 10^{-4}(\mathbf{m}) \mathrm{mol} /$ $\mathrm{dm}^{3} ; \mathrm{T}=298 \mathrm{~K}, \mathrm{I}=0.1$

only the ligand dissociation takes place in the solution and no other side reactions take place.

The value of the dissociation constant of the chrysin $(p K)$ was determined by the least square method from a set of $j$ and $\mathrm{pH}$ values. The results are listed in Table 2.

Table 2. Dissociations constants $p K$ of chrysin $(\mathrm{I}=0.1$ $\left.\left(\mathrm{NaClO}_{4}\right), \mathrm{T}=298 \mathrm{~K}\right)$

\begin{tabular}{|l|c|c|c|}
\hline \multirow{2}{*}{$\begin{array}{l}\text { Investigated } \\
\text { compound: } \\
\text { chrysin }\end{array}$} & \multicolumn{2}{|c|}{ Potentiometric data } & \multirow{2}{*}{$\begin{array}{l}\text { Liquid } \\
\text { chromatography }\end{array}$} \\
\cline { 2 - 3 } & $\begin{array}{c}\text { Rossotti } \\
\text { method }\end{array}$ & Solver & \\
\hline$p K$ & $7.65 \pm 0.19$ & $7.67 \pm 0.11$ & $7.10 \pm 0.01$ \\
\hline
\end{tabular}

In this paper, a simple nonlinear fitting method using Excel Solver (version 7.0) and user-defined functions was applied to evaluate the protonation constant $\left(\beta_{L}\right)$ of chrysin ${ }^{18}$. The following equation can be derived for potentiometric titration of chrysin (L):

$\beta_{L}\left[H^{+}\right]^{3}+\left(1+c_{Z} \beta_{L}\right)\left[H^{+}\right]^{2}+\left(c_{Z}-c_{L} \beta_{L} K_{w}\right)\left[H^{+}\right]-K_{w}=0(9)$

in which:

$c_{Z}=\frac{c_{0 Z} \cdot V_{Z}}{V_{Z}+V_{L}}$

The $\beta_{L}$ parameter must be found as the solution of the best fit using a nonlinear curve fitting procedure with a minimization of the sum of square of residual (SSR) $\left(\Sigma\left(p H_{\text {exp }}-p H_{\text {theo }}\right)^{2}\right)$.

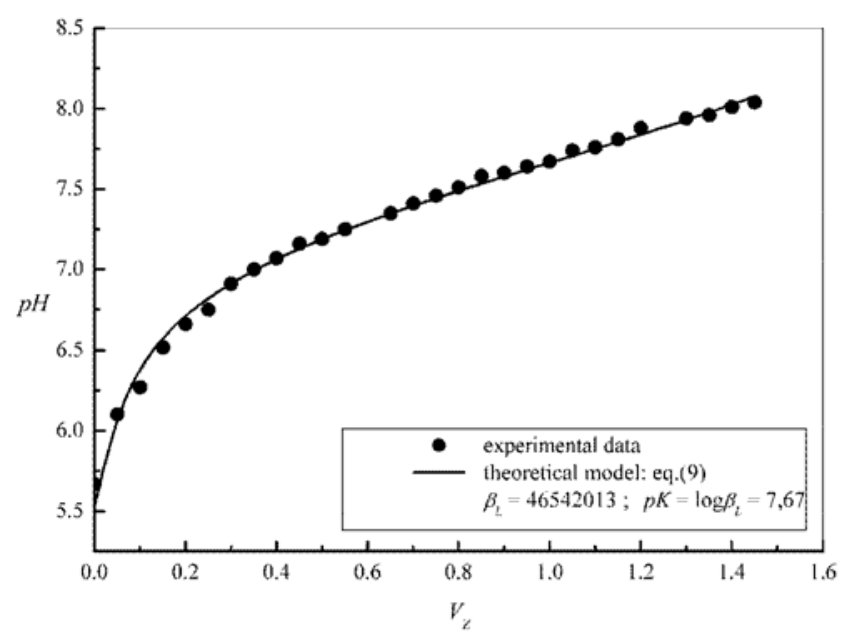

Figure 4. Evaluation of the protonation constant of chrysin according to eq.(9) for the concentration of chrysin $4.0 \cdot 10^{-4} \mathrm{~mol} / \mathrm{dm}^{3},(\mathrm{~T}=298 \mathrm{~K}, \mathrm{I}=0.1)$
Equation (9) is solved for $\left[\mathrm{H}^{+}\right]$by using the numerical Newton-Raphson method and applying the estimated value for $\beta_{L}$. Then, the theoretical $\mathrm{pH}\left(\mathrm{pH}_{\text {theo }}=-\log \left[\mathrm{H}^{+}\right]\right)$is calculated and the resulting SSR is minimized for finding the best fit values of $\beta_{L}$. The Solver options to determine $\beta_{L}$ were: precision $-1 \cdot 10^{-6}$; tolerance $-0.001 \%$; use automatic scaling; estimate - quadratic; derivatives - forward; search - Newton. The result of the estimation for the $4 \cdot 10^{-4} \mathrm{~mol} / \mathrm{dm}^{3}$ solution of chrysin is shown on Fig.4.

Table 2 shows the comparison of chrysin dissociation constant values determined by the above described methods. It can be seen that the differences in the evaluated $p K$ values are relatively small and do not exceed $1.2 \%$. Thus the proposed RP-TLC method can be used to determine the $p K$ values with accuracy comparable to classical analytical methods.

\section{SUMMARY}

- In this work the values of the first dissociation constant of chrysin were determined with the use of potentiometric and chromatographic methods. The second constant was not determined because, in these conditions (alkaline medium), chrysin is unstable.

- The methodology proposed in this work based on the RPTLC measurements gives comparable results with the potentiometric method of $p K$ evaluation in the case of chrysin as a test compound. The differences in the evaluated $p K$ values are relatively small and not exceed $1.2 \%$.

- The RP-TLC retention of different compounds in many cases depends strongly on the mobile phase $p H$ and on the $p K$ of the analyte in the mobile phase. For the determination of such physicochemical properties of different analytes the column chromatography (RP-HPLC) is mainly applied. The results of the investigations presented here show, that the RPTLC method may be important and very usable in the prediction of the dissociation constant for different test analytes and for the optimization of chromatographic separations.

- In order to better scrutinize the method proposed in this paper, one needs to perform an additional experimental study with different compounds.

\section{LITERATURE CITED}

1. Benavente-Garcia, O., Castillo, J., Marin, F.R., Ortuno A. \& Del Rio J.A. (1997). Uses and Properties of Citrus Flavonoids., J. Agric. Food Chem. 45(12), 4505 - 4515.

2. Di Carlo, G., Mascolo, N., Izzo A.A. \& Capasso F. (1999) Flavonoids: old and new aspects of a class of natural therapeutic drugs. Life Sci. 65(4), 337 - 353.

3. Harborne J.B. \& Mabry T.J. (1982). The Flavonoids Advances in Research. Chapman and Hall, London.

4. Cody, V., Middleton E. \& Harborne J. B. (1986). Plant Flavonoids in Biology and Medicine: Biochemical, Pharmacological and Structure-Activity relationships. Alan R. Liss, New York.

5. Cody, V., Middleton, E., Harborne J. B. \& Beretz A. (1988). Plant flavonoids in biology and medicine II: Biochemical, Cellular and Medicinal Properties. Alan R. Liss, New York,.

6. Pusz J. \& Nitka B. (1997). Synthesis and Physicochemical Properties of the Complexes of $\mathrm{Co}(\mathrm{III}), \mathrm{Ni}(\mathrm{III})$ and $\mathrm{Cu}(\mathrm{III})$ with Chrysin. Microchem. J. 56, 373 - 381.

7. Pusz J. \& Nitka B. (1996). Synthesis and physicochemical properties of the compounds of iron(III), cadmium(II) and lead(II) ions with chrysin. Zeszyty Naukowe Politechniki Rzeszowskiej. 14, 55 - 73, (in Polish).

8. Barcella, A.L., Grunwald, E., Marshall H.P. \& Purlee E.L. (1955). The potentiometric measurement of acid dissociation 
constants and $\mathrm{pH}$ in the system methanol-water. $\mathrm{pK}_{\mathrm{A}}$ values for carboxylic acids and anilinium ions. J. Org. Chem. 20, 747762.

9. Sheldovsky T. \& Kay R.L. (1956). The ionization constant of acetic acid in water-methanol mixtures at 250 from conductance measurements. J. Phys. Chem. 60(2), 151 - 155.

10. de Ligny, C.L. (1960). The dissociation constants of some aliphatic amines in water and methanol-water mixtures at $25^{\circ}$ C. Recl. Trav. Chim. Pays-Bas. 60, $731-746$.

11. de Ligny, C.L., Loriaux H. \& Ruiter A. (1961).The application of Hammett's acidity function Ho to solutions in methanol-water mixtures. Recl. Trav. Chim. Pays-Bas. 80, 725 739.

12. Chatten, L.G. \& Harris, L.E. (1962) Relationship between $\mathrm{pK}_{\mathrm{b}}\left(\mathrm{H}_{2} \mathrm{O}\right)$ of organic compounds and $\mathrm{E} / 2$ values in several nonaqueous solvents. Anal. Chem. 34, 1495 - 1501.

13. Lide, D.R. (1997 - 1998). Handbook of Chemistry and Physics (78th ed.) (pp. 3 - 78). CRC Press, New York.

14. Fried, B. \& Sherma, J. (1999) Thin-Layer Chromatography (Chromatographic Science, V. 81) (4th ed.). Marcel Dekker, USA.

15. Espinoza, S., Bosch E. \& Roses M. (2002). Retention of ionizable compounds in high-performance liquid chromatography. IX. Modelling retention in reversed-phase liquid chromatography as a function of $\mathrm{pH}$ and solvent composition with acetonitryle-water mobile phases. J. Chromatogr. A. 947, $47-58$.

16. Fletcher, R. (1971). A modified Marquardt sub-routine for nonlinear least-squares. AERE-R6799-Harwell - England.

17. Rossotti, H. (1983). The ions equilibria. PWN, Warsaw, Poland, (in Polish).

18. Maleki, N., Haghighi B. \& Safavi A. (1999). Evaluation of Formation Constants, Molar Absorptivities of Metal Complexes, and Protonation Constants of Acids by Nonlinear Curve Fitting Using Microsoft Excel Solver and User-Defined Function, Microchemical Journal. 62, 229 - 236. 